NBER WORKING PAPER SERIES

\title{
A FISCAL THEORY OF HYPERDEFLATIONS? SOME SURPRISING \\ MONETARIST ARITHMETIC
}

Willem H. Buiter

Technical Working Paper No. 52

NATIONAL BUREAU OF ECONOMIC RESEARCH 1050 Massachusetts Avenue

Cambridge, MA 02138

October 1985

The research reported here is part of the NBER's research program in Financial Markets and Monetary Economics. Any opinions expressed are those of the author and not those of the National Bureau of Economic Research. 
NBER Technical Working Paper \#52

November 1985

A Fiscal Theory of Hyperdeflations? Some

Surprising Monetarist Arithmetic

\section{$\underline{\text { ABSTRACT }}$}

The note mines an unsuspected lode in the Sargent-Wallace "Unpleasant Monetarist Arithmetic" deposit. While that model is shown to be incapable of generating hyperinflations as a result of large monetized public sector deficits, it can generate hyperdeflations or perhaps more accurately, the first stages of an unsustainable process of hyperdeflation. The drawing of policy conclusions is left as an exercise for the reader.

Willem H. Buiter Economic Growth Center Yale University 37 Hillhouse Avenue New Haven, CT 06520 


\section{A Fiscal Theory of Hyperdeflations? Some \\ Surprising Monetarist Arithmetic}

Willem H. Buiter

(Yale and NBER)

In a paper that has already become a classic, Sargent and Wallace (1981) explored some unfamiliar implications of the government budget constraint and proposed a "fiscal theory of inflation." Once the real per capita stock of non-monetary, interest-bearing government debt stabilizes (say because it reaches some upper 1 imit reflecting real resource constraints), and with the primary deficit (the public sector deficit net of interest payments) treated as exogenous, monetary growth is endogenous1y or residually determined by the requirement that the real value of seigniorage (the real value of nominal money stock increases) should satisfy the government budget constraint. Their paper then goes on to analyze the consequences for inflation, in the short run and in the long run, of short-run changes in monetary growth not accompanied by changes in the primary deficit. Elsewhere I have commented at length on that issue (Buiter (1983)). This short note focuses on a neglected aspect of the Sargent-Wallace model: its Implications for the nascent theory of hyperdeflations. It is shown how, according to the equation of motion alone, a sufficiently large fiscal deficit will result in unstable, explosive behavior of the money growth rate, the inflation rate, and the stock of real money balances. This explosive process, however, is not a hyperinflation but a hyperdeflation: the rates of money growth and inflation decline and the per capita real money stock increases without bound. Such behavior obviously is not sustainable, and the model's side-conditions make this clear. In the 
Sargent-Wallace two-period, two-class overlapping generations mode1, the real stock of money balances equals the saving out of period one income (and the purchases of consumption goods in the second period of their lives) by the poor. Income and the supply of consumer goods are bounded; an unbounded real money stock therefore cannot characterize an equilibrium. That notwithstanding, I w11 suggest that the Sargent-Wallace mode1 may temporarily generate a bit of hyperdeflation, before the unsustainability of their trajectory dawns on the inhabitants of the Sargent-Wallace universe and the model disappears off the page. In any case, in the Sargent-Wallace model, deficits can never generate hyperinflations. The paucity of empirical data on hyperdeflations (indeed their absence) should not be a deterrent to a thorough theoretical analysis of the phenomenon. After all, a large fraction of the profession has worked and is now working on the theory of general competitive equilibrium.

I shall present the model in continuous time, rather than in the original discrete-time format, because of the presentational usefulness of continuous time phase-diagrams. The exact same points can, however, be made using the discrete time model. m denotes the real per capita stock of money balances; $b$ the real per capita stock of interest-bearing public debt; $\delta$ the real per capita primary deficit; $r$ the exogenous real interest rate; $\mathrm{n}$ the exogenous proportional growth rate of the population; and $\pi$ the rate of inflation. The real per captia stock of debt is kept constant at a given value $b=\bar{b}$. Nominal bond issues, $\dot{B}$ are therefore fust sufficient to offset the erosion in the real per capita stock of bonds due to population growth and inflation: $\dot{B}=(n+\pi) B$. The government budget constraint then implies that

$$
\text { (1) } \dot{\mathrm{m}}=\delta+(\mathrm{r}-\mathrm{n}) \overline{\mathrm{b}}-(\pi+\mathrm{n}) \mathrm{m}
$$


It is assumed until further notice, that $\delta+(r-n) \vec{b}>0$. The per capita demand for real money balances depends inversely on the expected rate of inflation. Rational inflation expectations prevail

$$
\begin{array}{ll}
\text { (2a) } m=\gamma_{1}-\gamma_{2} \pi & \gamma_{1}, \gamma_{2}>0 \\
\text { (2b) } 0<m<\bar{m} &
\end{array}
$$

$\overline{\mathrm{m}}$ is the upper bound on the real per capita money stock referred to earlier. Substituting (2a) into (1) we obtain

(3) 自 $=\delta+(r-n) \bar{b}-\left(\gamma_{2}^{-1} \gamma_{1}+n\right) m+\gamma_{2}^{-1} m^{2}$

This differential equation either has two, one or zero stationary equilibria. The three cases are 1llustrated in Figure $1 a, b, c$. In Figure (1a) $\mathrm{m}_{1}^{*}$ is the locally unstable low inflation stationary equilibrium. $m_{2}^{*}$ is the locally stable high inflation stationary equilibrium. It is easily checked that

(4) $m_{1,2}^{*}=\frac{\gamma_{1}+n \gamma_{2} \pm\left[\left(\gamma_{1}+n \gamma_{2}\right)^{2}-4 \gamma_{2}(\delta+(r-n) \bar{b})\right]^{1 / 2}}{2}$

The case with two stationary equilibria corresponds to "sma11" deficts $\left(\delta+(r-n) \bar{b}<\frac{\left(\gamma_{1}+n \gamma_{2}\right)^{2}}{4 \gamma_{2}}\right)$. The case with no stationary equilibrium corresponds to "large" deficits $\left(\delta+(r-n) \bar{b}>\frac{\left.\left(\gamma_{1}+n \gamma_{2}\right)^{2}\right)}{4 \gamma_{2}}\right)$.

In their paper Sargent and Wallace considered only the small deficit case depicted in Figure (1a). They also opted for the locally unstable low inflation steady state $\mathrm{m}_{1}^{*}$. Presumably, this choice was prompted by analogy with the common practice, in linear rational expectations models, of associating non-predetermined state variables with unstable eigen values. 


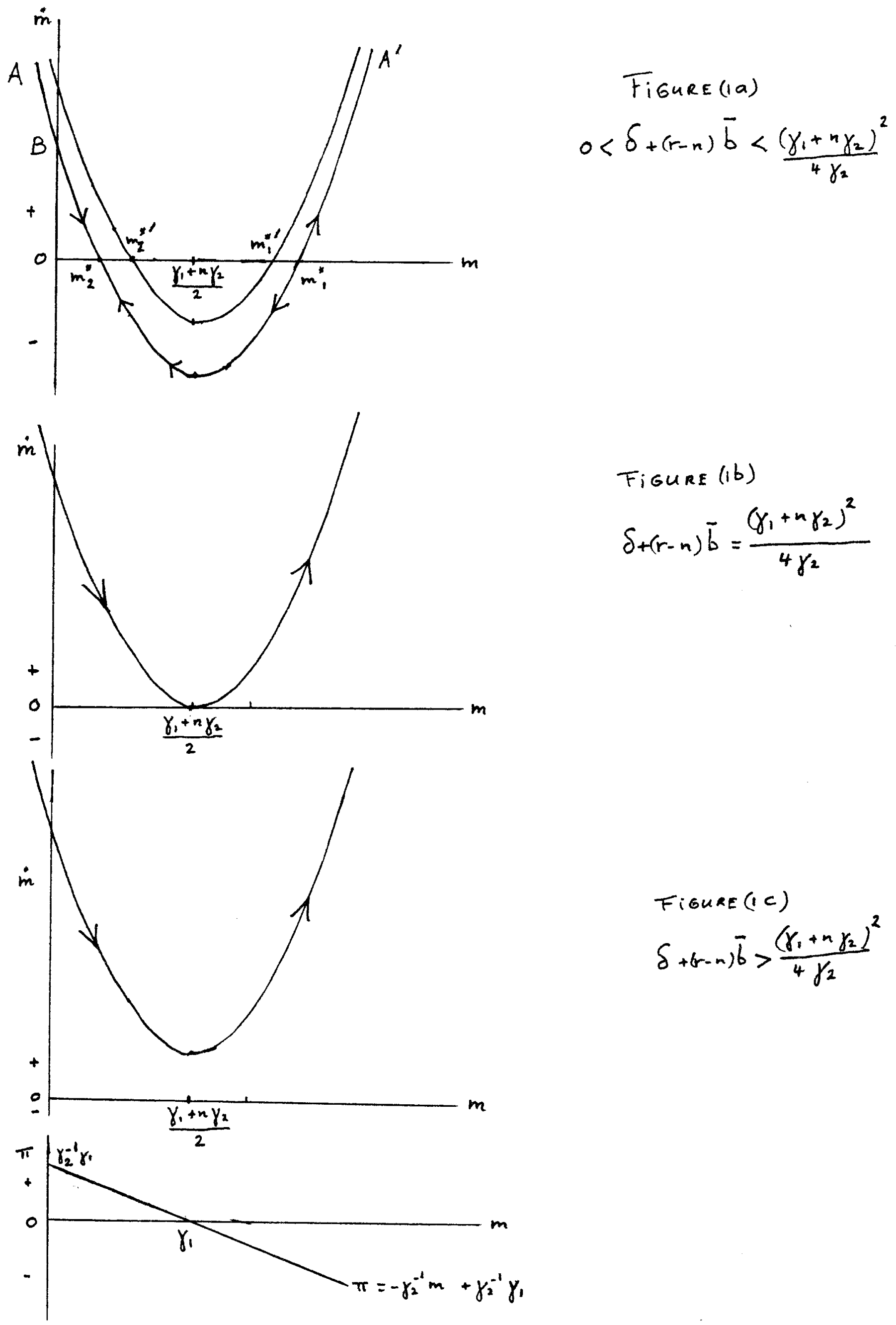


The general price level in this classical, flexible price model is non-predetermined and so therefore is $\mathrm{m}$.

The transversality or terminal boundary condition that the system should converge continuously (except possibly at moments when 'news' arrives) to a steady state, for constant values of the forcing variables, only suffices to determine a unique initial value for $m$ if the steady state equilibrium in question is $m_{1}^{*}$. If the terminal boundary condition required convergence to $\mathrm{m}_{2}^{*}$, any initial value of $m$ on $A^{\prime}$ to the left of $\mathrm{m}_{1}^{*}$ and to the right of $B$ would be eligible. There would seem to be no economic rationale for choosing $\mathrm{m}_{1}^{*}$ rather than $\mathrm{m}_{2}^{*}$. If $\mathrm{m}_{1}^{*}$ is a feasible stationary solution $\left(m_{1}^{*}<\bar{m}\right)$ then so is $m_{2}^{*}$. No economic or physical constraints will impede solutions moving toward $\mathrm{m}_{2}^{*}$ from anywhere between $B$ and $\mathrm{m}_{1}^{*}$.

The issue as to whether there exist, for the small deficit case depicted in Figure (la), reasonable economic restrictions that allow one to choose a unique convergent solution from among the continuum of solutions that converge to $\mathrm{m}_{2}^{*}$ is not resolved here. Instead I propose to focus on the two diagrams in Figure (1c), which depict the explosive, non-stationary behavior that will be exhibited when this economy has large deficits $\left(\delta+(r-n) \bar{b}>\frac{\left.\left(\gamma_{1}+n \gamma_{2}\right)^{2}\right)}{4 \gamma_{2}}\right.$.

When the real per capita debt stock is constant, larger deficits (strictly speaking larger inflation-and-real-growth-corrected government current full employment account deficits) require more seigniorage revenue, that is, a greater yield of the inflation tax. Let $\mu$ denote the 
proportional rate of growth of the nominal money stock and $\sigma$ real per capita seigniorage: $\sigma \equiv \mu \mathrm{m}$. In a steady state $\sigma=\gamma_{2}^{-1} \mathrm{~m}^{2}-\left(\gamma_{2}^{-1} \gamma_{1}+\mathrm{n}\right) \mathrm{m}$. The value of $\mathrm{m}, \hat{\mathrm{m}}$ say, that maximizes steady-state seigniorage is given by:

$$
\text { (5a) } \hat{\mathrm{m}}=\frac{r_{1}+\mathrm{n} \gamma_{2}}{2}
$$

The maximum steady-state value of seigniorage is:

$$
\text { (5b) } \hat{\sigma}=\frac{\left(\gamma_{1}+n \gamma_{2}\right)^{2}}{4 \gamma_{2}}
$$

The steady-state seigniorage maximizing rate of inflation is

$$
\text { (5c) } \hat{\pi}=\frac{1 / 2\left(\gamma_{1}-n\right)}{\gamma_{2}}
$$

Not surprisingly, the large deficit case depicted in Figure (1c) is the one for which it is not possible to find a steady state in which the inflation tax is sufficient to close the budget gap $(\delta+(r-n) \bar{b}>\hat{\sigma})$. It is possible, however, (at least until $\mathrm{m}>\overline{\mathrm{m}}$ ) to generate the necessary selgniorage revenue in a non-steady state manner. While the high deficit economy depicted in Figure (1c) cannot raise the necessary seignorage at a constant rate of inflation and a constant value of $m$, it can generate the required inflation tax revenue with a steadily rising stock of real per capita money balances and steadily falling rates of inflation and nominal money stock growth.

A lower rate of nominal money growth will be associated with an increase in real per capita seignorage if the elasticity of money demand with respect to the rate of monetary growth exceeds unity $\left(n m \mu=\frac{-\mu d m}{m d \mu}>1\right)$ 
From the money demand function (2a) we see that the effect on real seigniorage of a reduction in money growth is given by

$$
\gamma_{1}-\gamma_{2} \pi-\mu \gamma_{2} \frac{d \pi}{d \mu}
$$

In steady states, $\pi=\mu-n$ and the steady-state effect on real seigniorage of a permanent reduction in the rate of growth of nominal money is positive If $\mu>\frac{1 / 2\left(\gamma_{1}+n\right)}{\gamma_{2}}$, the steady-state real seigniorage maximizing rate of money growth. This will occur, for example, if in Figure (1a) the initial stationary equilibrium is the locally stable $m_{2}^{*}$. A larger deficit will in that case be associated with a new long-run equilibrium such as $\mathrm{m}_{2}^{*}$ with a lower rate of money growth and a lower rate of inflation. Both $\mathrm{m}_{2}^{*}$ and $\mathrm{m}_{2}^{*}$, are on the wrong side of the long-run "selgniorage Laffer curve." If the relevant stationary equilibrium is the locally unstable $\mathrm{m}_{1}^{\star}$, a lower rate of money growth wi11, comparing steady states, be associated with a smaller real seigniorage revenue. Larger deficits are associated with increased inflation In the long run.

For a given real per capita deficit (i.e., along a given solution parabola in Figures $l a, b$, or $c$ above), constant real per capita seigniorage revenue equal to $\delta+(r-n) \bar{b}$ is generated at every instant, both when the long-run money demand schedule is elastic (for high $\pi$ ) and when it is Inelastic (for low $\pi$ ). $1 /$ Consider, for example, the explosive large defic1t case depicted in Figure (1c). With m rising, $\pi=-\gamma_{2}^{-1} m+\gamma_{2}^{-1} \gamma_{1}$ falling,

\footnotetext{
1/ Obviously along any given solution parabola, the instantaneous elasticity of money demand with respect to the rate of money growth, $\eta_{m} \mu$ equals unity.
} 
and $\mu=\frac{\delta+(r-n) \bar{b}}{m}$ falling, the same amount of real seigniorage is raised with a steadily falling inflation tax rate and a steadily expanding inflation tax base. I/

Thus the price of fiscal irresponsibility appears to be hyperdeflation. Clearly, if such a process got underway it could not be sustained because of the real resource constraints that set an upper bound on $m$. There exists a view of rational expectations models which holds that a process that cannot be sustained would not get started. I consider such a view to be unnecessarily restrictive and would regard as admissable those solution trajectories that spend some time on an explosive, unsustainable course. Even if one rejects the conclusion that the Sargent-Wallace model generates hyperdeflation as a result of large inflation-and-real-growth corrected public sector current account deficits, there is no way in which that model can ever generate hyperinflation. If the hyperdeflation case (Figure (1c)) is ruled out, then there is simply no solution to the large deficit $[\delta+(r-n) \bar{b}>\hat{\sigma}]$ case. There isn't a hyperinflation solution. If we are in the small deficit case $(0<\delta+(r-n) \bar{b}<\hat{\sigma})$ of Figure (1a) an increase

$1 /$ Note that, if $\mathrm{m}>0$ and $\delta+(r-n) \bar{b}>0, \mu$ always remains positive for finite values of $m$. $\pi$ is a linear decreasing function of $m$ and will be negative for $m>\gamma_{1}$. There will be an increasing divergence between the growth rate of the nominal money stock and the rate of inflation, since $\frac{\mathrm{d} \pi}{\mathrm{d} \mu}=\frac{\mathrm{m}^{2}}{(\delta+(\mathrm{r}-\mathrm{n}) \overline{\mathrm{b}}) \gamma_{2}}$ increases with $\mathrm{m}$. 
in the deficit can either raise the long-run rate of inflation (if we choose the locally unstable equilibrium) or lower the long-run rate of inflation (if we choose the locally stable equilibrium). Even when the long-run inflation rate increases, this increase is a finite one, not a run-away explosive hyperinflation.

Now consider the case where the inflation-and-real growth connected government current account deficit is negative: $\delta+(r-n) \bar{b}<0$. This government surplus economy is depicted in Figure (2). $\delta+(r-n) \bar{b}$ is measured by the intersection of the parabola with the vertical $\dot{m}$ axis at $B$. Note that as long as $\gamma_{1}+n \gamma_{2}>0$, there will still be one stationary equilibrium with a positive value of $m$, the unstable one at $m_{1}^{*}$. If we consider only non-negative values of $m$ to be admissable and if we impose the "no-bubble" transversality condition that if there exists a convergent solution, the economy will pick it, solutions will be unique. The response of the system to a reduction in the surplus then is the same as the response to an increase in the deficit in Figure (la) when the locally unstable stationary equilibrium $\mathrm{m}_{1}^{*}$ is considered to be the relevant one. The long-run effect (and also the impact effect if the reduction in the surplus is unanticipated, immediate and permanent) is a finite increase in the rate of inflation. If we admit bubbles, the system could either move north-east along $\mathrm{m}_{1}^{*} \mathrm{~A}^{\prime}$ (the hyperdeflation case) or along $\mathrm{m}_{1}^{*} \mathrm{~B}$ with a falling $m$ and a rising rate of inflation. Even when $m$ hits zero, at $B$, the rate of inflation is only $\gamma_{2}^{-1} \gamma_{1}$. This may seem paradoxical until it is realized that $m$ becomes equal to zero not because the price level becomes infinite with a positive nominal money stock, but because the 


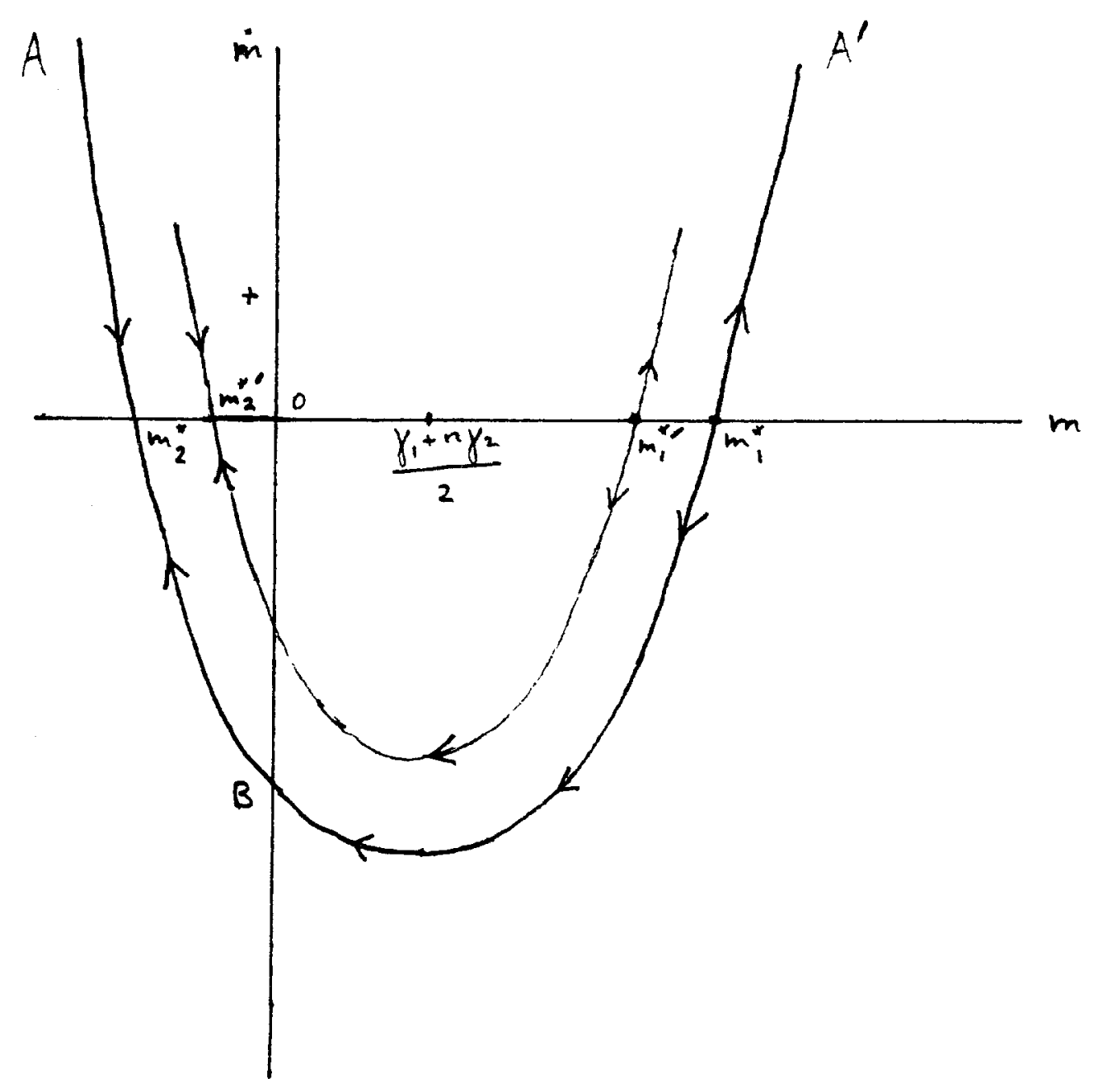

Figure 2.

$$
\delta+(r-n) \bar{b}<0<\frac{\gamma_{1}+n \gamma_{2}}{2}
$$


nominal money stock declines to zero with a finite (if rising) price level as the government uses its surpluses to contract the nominal money stock. The grounds for confining the analysis (in Figures ( $1 \mathrm{a}, \mathrm{b}$, and c) as well as in Figure (2)) to a non-negative real money stock then become rather shaky. It is indeed simple to modify the Sargent-Wallace model in such a way as to permit the poor private agents to borrow from the government by issuing monetary liabilities. Negative values of $m$ then simply reflect negative values of the nominal money stock, $1 . e .$, a net creditor position of the government vis-à-vis its poor citizens. The case of Figure 2 then becomes in all important respects the same as the small deficit case depicted in Figure (1a). Whichever way one turns it, the model cannot generate a hyperinflation.

While there is a certain scarcity of empirical observations on hyperdeflations, one can take encouragement from the thought that among the many countries now facing intractable budgetary deficits, there are likely to be a few that will be compelled to monetize these deficits at ever decreasing rates of monetary growth. The United States might even be the place where this new chapter in monetary history is written. 


\section{References}

Bulter, W.H. [1983] "Deficits, Crowding Out and Inflation: The Simple Analytics" NBER Working Paper No. 1078, February 1983.

Sargent, T.J. and N. Wallace [1981] "Some Unpleasant Monetarist Arithmetic" Federal Reserve Bank of Minneapolis Quarterly Review 5, Fa11, Pp. 117 